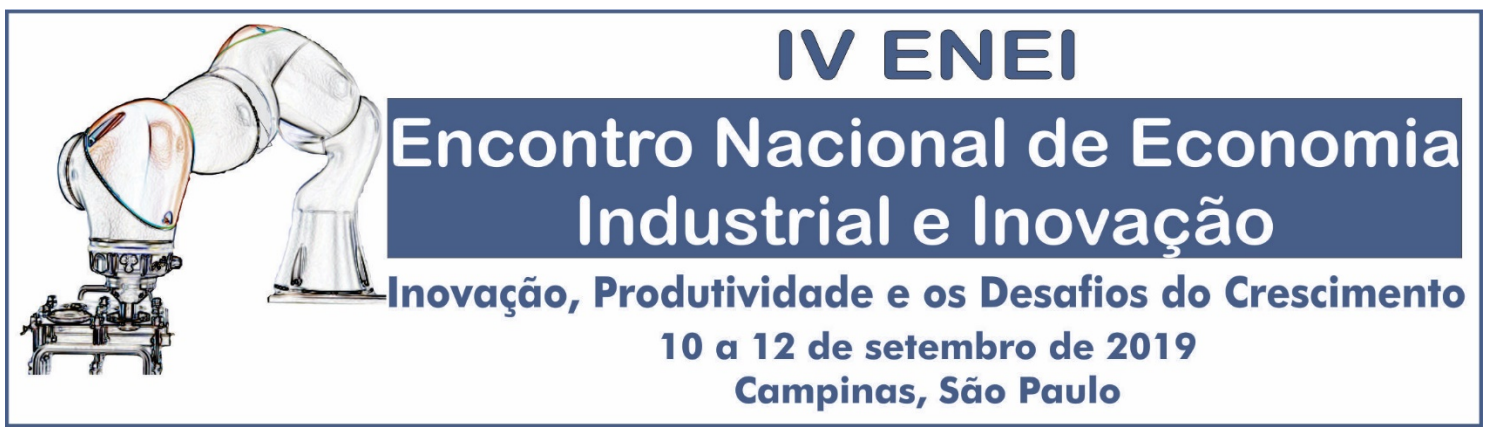

\title{
TRANSFERÊNCIA DE TECNOLOGIA E ECONOMICIDADE NAS PARCERIAS PARA O DESENVOLVIMENTO PRODUTIVO DO MINISTÉRIO DA SAÚDE
}

\author{
Ricardo Lobato Torres ${ }^{1}$
}

Alexandra Patricia Albareda ${ }^{2}$

\begin{abstract}
RESUMO
As Parcerias para o Desenvolvimento Produtivo são uma política do Ministério da Saúde para internalização da tecnologia de produção de medicamentos e insumos estratégicos para o Sistema Único de Saúde. Os instrumentos da política combinam o uso do poder de compra do governo federal, investimento nos laboratórios públicos e incentivos aos parceiros privados proprietários da tecnologia para sua transferência a produtores nacionais públicos e privados. Um dos principais objetivos da política é reduzir o preço de aquisição de medicamentos de alto custo. Neste sentido, este artigo faz uma análise da evolução dos preços reais dos medicamentos alvo da política, a fim de avaliar se a economicidade almejada pela política está sendo alcançada. Para os onzes medicamentos analisados neste estudo, apenas dois não apresentaram economicidade compatível com a política. Além da redução de preços, foi observado ainda o aumento nas quantidades adquiridas, permitindo a ampliação da oferta dos produtos no SUS.
\end{abstract}

Palavras-chave: transferência de tecnologia; política industrial; parcerias para o desenvolvimento produtivo; sistema único de saúde; poder de compra do Estado.

\begin{abstract}
The Partnerships for Productive Development are a Ministry of Health policy to internalize the production technology of drugs and inputs considered strategic for the Brazilian public health system. The policy instruments combine the federal government purchasing power, investments on public laboratories and incentives for private technologies owners to transfer their technologies to national producers, both public and private. One of the main goals of the policy is to reduce the purchase price of high-cost drugs. In this sense, this article analyzes the evolution of the real prices of the drugs targeted by the policy, in order to evaluate if the intended cost-savings is being achieved. For the eleven drugs analyzed in this study, only two were not economically compatible with the policy. In addition to the price reduction, the increase in the quantities acquired was also observed, allowing the expansion of the supply of products in the public health system.
\end{abstract}

Keywords: technology transfer; industrial policy; partnerships for productive development; public health system; government purchasing power.

Área ABEIN: 6.1 - Políticas Industriais e Comerciais

Classificação JEL: I18, L52.

\footnotetext{
${ }^{1}$ Professor do Departamento Acadêmico de Gestão e Economia, UTFPR, rltorres@utfpr.edu.br.

${ }^{2}$ Mestranda do Programa de Pós-Graduação em Planejamento e Governança Pública, UTFPR, alexandra.albareda@gmail.com.
} 


\section{Introdução}

As Parcerias para o Desenvolvimento Produtivo (PDPs) são uma política do Ministério da Saúde para internalização da tecnologia de produção de medicamentos e insumos estratégicos para o Sistema Único de Saúde (SUS). Trata-se de parcerias público-privadas que visam a transferência de tecnologia de produção de produtos de saúde (medicamentos, vacinas, soros, insumos, equipamentos médico-hospitalares e dispositivos de diagnóstico) para os laboratórios farmacêuticos oficiais, isto é, para a rede pública de laboratórios. O alvo dessas parcerias são os chamados insumos estratégicos do SUS, uma relação de medicamentos e outros produtos de alto-custo de aquisição, fornecidos geralmente por uma única empresa, cuja produção é feita no exterior (TORRES, 2016a).

A política das PDPs surgiu com um objetivo triplo. O primeiro e mais evidente é o de reduzir o preço de aquisição de insumos estratégicos. O segundo é o de promover a nacionalização da produção, contribuindo assim para a redução no déficit comercial em produtos farmacêuticos. $\mathrm{O}$ terceiro e último objetivo é o de tentar recuperar financeira e tecnologicamente os laboratórios farmacêuticos oficiais, sucateados ao longo das décadas de 1980 e 1990 (VIANA et al., 2016).

É um curioso modelo de industrialização por substituição de importações que não infringe as regras dos tratados da Organização Mundial do Comércio (OMC), da qual o Brasil é signatário. Por um lado, essa política revela uma tentativa do governo federal de reeditar o desenvolvimentismo da década de 1950. Por outro, apresenta instrumentos inovadores de política industrial ao estabelecer incentivos de mercado para atrair os detentores da tecnologia original ou de tecnologias similares. Isso foi possível porque muitos dos produtos-alvo da política têm sua patente expirada ou em vias de expirar ao longo do período do contrato da parceria (TORRES, 2016b).

Os primeiros contratos dessa política são datados de 2009. Apesar disso, a efetiva regulação da operacionalização da política ocorreu apenas em 2012, com revisões sucessivas em 2014 e 2017 (BRASIL, 2012a; 2014; 2017a). Decorrida uma década desde o seu início, alguns contratos já foram encerrados, com a tecnologia incorporada ao SUS, como é o caso da rivastigmina produzido pelo Instituto Vital Brazil (IVB), e do tenofovir produzido pelo Laboratório Farmacêutico de Pernambuco (LAFEPE) e pela Fundação Ezequiel Dias (FUNED). De acordo com os dados do próprio Ministério da Saúde, em 2019 estavam vigentes 97 parcerias, sendo 92 delas para medicamentos, soros e vacinas, em diferentes fases de incorporação das tecnologias-alvo (BRASIL, 2019).

Embora a política das PDPs apresente múltiplos objetivos, este artigo se limita à análise da materialização da redução dos preços reais dos produtos de saúde. Ainda que as normativas da política versem sobre a economicidade e vantajosidade, considerando preços, qualidade, tecnologia e benefícios sociais, apenas o primeiro critério é avaliado neste estudo. Para isso, foi realizado um comparativo do valor das compras dos períodos anteriores e posteriores às PDPs, controlados pelo índice oficial de inflação. Essa análise limitou-se aos casos com dados disponíveis e com aquisições já realizadas pelo Ministério da Saúde após a assinatura de contrato com os parceiros públicos e privados. É importante notar que as PDPs se utilizam de um dispositivo de dispensa de licitação, possibilidade introduzida em 2012 na lei de licitações (BRASIL, 2012b). Logo, a economicidade e a transferência de tecnologia ao SUS são condições necessárias para compensar a dispensa de licitação e concorrência para provimento de produtos de saúde ao governo federal.

O artigo está estruturado em cinco seções, incluindo esta introdução. Na seção 2 é apresentado o contexto da formulação da política, bem como o detalhamento da sua operacionalização. A seção 3 descreve os métodos da pesquisa para a análise da economicidade das compras governamentais por meio das PDPs. A seção 4 apresenta e discute os resultados da pesquisa. A quinta e última seção traz as conclusões do estudo. 


\section{A Política Industrial do Ministério da Saúde}

Considerando o cenário econômico dos anos 1990, observa-se a retração da indústria da saúde e a perda da competitividade do parque industrial, bem como o afastamento do Estado como agente indutor do desenvolvimento industrial, exatamente no momento em que a demanda por produtos e serviços de saúde aumentou em decorrência da implantação do Sistema Único de Saúde. Isso acarretou crescente fragilidade da base produtiva. Foi apenas a partir dos anos 2000 que a visão até então predominante sobre política industrial começou a mudar, por meio da adoção de políticas que trouxeram à tona a preocupação com a inovação e a competitividade da indústria a nível internacional, ao mesmo tempo em que surgia a preocupação com o desenvolvimento de uma base produtiva nacional (GADELHA; BRAGA, 2016).

Após anos sem um planejamento concreto em termos de política industrial, o governo lançou a Política Industrial, Tecnológica e de Comércio Exterior (PITCE), em 2004. Composta por 57 medidas distribuídas em 11 programas setoriais, consistia em um plano de ação do governo federal que tinha como objetivo o aumento da eficiência da estrutura produtiva, da capacidade de inovação das empresas brasileiras e a expansão das exportações (ARAÚJO JUNIOR, 2015). Para dar suporte à política, no mesmo ano foi editada a Lei $n^{\circ} 10.973$, conhecida como a Lei de Inovação Tecnológica, estabelecendo "medidas de incentivo à inovação e à pesquisa científica e tecnológica no ambiente produtivo, com vistas à capacitação tecnológica, ao alcance da autonomia tecnológica e ao desenvolvimento do sistema produtivo nacional e regional do País" (BRASIL, 2004a).

Posteriormente, em 2008, foi lançada a Política de Desenvolvimento Produtivo (PDP), uma continuidade da PITCE com maiores pretensões. Seu objetivo era "fomentar o setor industrial através de incentivos creditícios, subsídios, isenção e redução de tributos e marcos regulatórios para algumas atividades setoriais" (CORONEL et al., 2011). Da mesma forma que a política anterior, a PDP apresentou medidas visando o fortalecimento da economia do país por meio do aumento da produtividade e competitividade da indústria nacional, no entanto, ampliou o leque de setores, priorizando 25 deles em detrimento dos quatro priorizados pela PITCE (DIEESE, 2008; IEDI, 2008).

A terceira política industrial foi o Plano Brasil Maior (PBM), editado em 2011 com vigência até 2014, com os objetivos de "acelerar o crescimento do investimento produtivo e o esforço tecnológico e de inovação das empresas nacionais, e aumentar a competitividade dos bens e serviços nacionais" (BRASIL, 2011). De forma a auxiliar na formulação de programas e projetos a partir de diretrizes setoriais, temáticos e que englobassem mais de um setor, o PBM dividiu os setores estratégicos em cinco blocos, sendo o primeiro deles o de sistemas da mecânica, eletroeletrônica e saúde. Gadelha e Costa (2012) afirmam que o PBM, assim como a PITCE, reafirmou o protagonismo da saúde como um dos segmentos estratégicos a serem fomentados no Brasil.

Para Gadelha (2012), no âmbito da economia política, há uma necessidade de recuperação do pensamento desenvolvimentista, de refletir sobre aprendizado e inovação para garantia do desenvolvimento. Nesse aspecto, segundo o autor "a saúde como qualidade de vida implica pensar em sua conexão estrutural com o desenvolvimento econômico, a equidade, a sustentabilidade ambiental e a mobilização política da sociedade". Assim, a saúde, além de ser um elemento estruturante do bem-estar, inerente à dimensão social do desenvolvimento, passou a ser vista como um espaço econômico interdependente, que configura um sistema de inovação e um sistema produtivo, sendo parte inerente também do desenvolvimento econômico do país.

Dessa maneira, foi proposto o conceito de Complexo Econômico-Industrial da Saúde (CEIS) como uma forma de explicar a característica sistêmica da saúde, reconhecendo que para o atendimento da demanda da sociedade por bens e serviços inerentes a esse setor, existe uma base 
produtiva que se responsabiliza pela sua oferta (GADELHA; COSTA; MALDONADO, 2012). Portanto, o CEIS se caracteriza por essa dinâmica que converge determinados setores industriais e serviços sociais destinados à prestação de cuidados em saúde, evidenciando uma visão integral que compreende que o capital e o social devem afluir em prol de um objetivo comum, que é a prestação equânime e universal da saúde.

Buscando uma definição de Complexo Industrial da Saúde (CIS ou CEIS), verifica-se que Gadelha (2003) introduz esse conceito ao buscar uma junção da área da saúde e do complexo industrial, mostrando que não há como pensar em desenvolvimento nacional sem articular as políticas industriais e tecnológicas com a política de saúde, reconhecendo dessa forma, inclusive, a natureza capitalista da área da saúde, algo essencial para a busca do lucro e de mercados e o atendimento às necessidades sociais e individuais.

O conceito de CEIS se sustenta, ainda, pela teoria neoschumpeteriana, privilegiando a atividade produtiva e a capacidade inovativa, medida pela capacidade empresarial de transformar conhecimento em novos produtos e/ou processos, ou melhorar de forma significativa os já existentes, imprimindo à saúde um papel multifacetado, colocando-a como um dos eixos principais do desenvolvimento nacional (ALMEIDA, 2018).

O CEIS é, portanto, um componente estratégico na busca de garantir saúde com qualidade à população (SILVA, 2014). E, para que os serviços possam ser realizados e o atendimento à população seja efetivado, é necessária a produção de uma grande quantidade de bens oriundos de setores industriais diferentes, que, dentro do CEIS, são organizados em dois grandes blocos: as indústrias de base química e biotecnológica (indústria farmacêutica, vacinas, hemoderivados e reagentes para diagnóstico), e as de base mecânica, eletrônica e de materiais (equipamentos e materiais médicos). Além disso, o CEIS é formado pelo segmento de serviços, que nada mais é do que a confluência dos dois grandes segmentos industriais, pois a prestação do serviço requer os bens e inovações trazidos pela indústria.

A Constituição Federal de 1988 reconheceu a saúde como um direito de todos e dever do Estado, devendo ser prestada de maneira equitativa, integral e universal (BRASIL, 1988). Assim, a saúde passa a receber uma atenção especial do ponto de vista político, jurídico e social, demandando do Estado a garantia da sua prestação por meio do estabelecimento de leis e políticas públicas eficazes.

Uma das maiores garantias constitucionais foi a criação de um sistema universal de saúde, chamado de Sistema Único de Saúde (SUS), regulamentado posteriormente pela lei 8.080, de 19 de setembro de 1990 (BRASIL, 1990). O SUS pode ser caracterizado como uma rede regionalizada de ações e serviços públicos de saúde, sendo constituído por serviços da União, dos estados, do Distrito Federal e dos municípios, que, de maneira integrada, prestam os serviços e ações necessários para a efetivação do direito à saúde. Atualmente, a distribuição entre os entes federativos ocorre de maneira que os municípios possuem a tarefa de cuidar da atenção básica, enquanto os serviços de média e alta complexidade (atenção secundária e terciária) ficam a cargo dos municípios mais desenvolvidos, dos estados e, excepcionalmente, da União (AITH et al., 2014).

O artigo 200 da Constituição Federal de 1988 estabeleceu as competências do SUS, destacando-se entre elas, o incremento do desenvolvimento científico e tecnológico na área da saúde no país e a prestação de assistência terapêutica integral, inclusive farmacêutica, sendo dever do Estado a formulação da política de medicamentos (BRASIL, 1988). De maneira a regulamentar essa parte específica do texto legal, em 2001 a assistência farmacêutica foi garantida por meio da Política Nacional de Medicamentos (PNM), com o propósito de "garantir a necessária segurança, eficácia e qualidade dos medicamentos, a promoção do uso racional e o acesso da população àqueles considerados essenciais" (BRASIL, 2001), apresentando entre suas diretrizes a necessidade da 
adoção de uma relação de medicamentos essenciais, ou seja, aqueles considerados básicos e indispensáveis para atender a maioria dos problemas de saúde da população. Ainda, em 2004, o Ministério da Saúde publicou a Resolução no 338, de 06 de maio, aprovando a Política Nacional de Assistência Farmacêutica (PNAF), considerada como parte integrante da Política Nacional de Saúde, "envolvendo um conjunto de ações voltadas à promoção, proteção e recuperação da saúde e garantindo os princípios da universalidade, integralidade e equidade" e tendo o medicamento como insumo essencial para esse fim (BRASIL, 2004b).

Assim, as Parcerias para o Desenvolvimento Produtivo (PDPs) surgiram como uma política destinada a "ampliar o acesso a medicamentos e produtos para saúde considerados estratégicos para o Sistema Único de Saúde (SUS), por meio do fortalecimento do complexo industrial do país" (BRASIL, 2012; BRASIL, 2017a).

Como consequência dessa política, diversos regulamentos e decretos foram elaborados buscando a consecução dos objetivos de desenvolvimento e inovação dentro do CEIS. Inicialmente, foi publicada a Portaria $n^{\circ} 374$, de 28 de fevereiro de 2008, que instituiu no âmbito do Sistema Único de Saúde o Programa Nacional de Fomento à Produção Pública e Inovação no Complexo Industrial da Saúde. De acordo ao artigo $2^{\circ}$ da portaria, o objetivo do programa é promover o fortalecimento e a modernização do conjunto de laboratórios públicos encarregados da produção de medicamentos e imunobiológicos de relevância estratégica para o SUS. E para atingir esse objetivo busca-se a ampliação da participação no Complexo Produtivo da Saúde, contribuindo para a redução da defasagem tecnológica existente, além do desenvolvimento econômico, científico e tecnológico do País (BRASIL, 2008a).

No mesmo ano foi publicado o Decreto DNN, de 12 de maio, o qual cria, no âmbito do Ministério da Saúde, o Grupo Executivo do Complexo Industrial de Saúde (GECIS) (BRASIL, 2008 b), cuja regulamentação foi atualizada por meio do Decreto $n^{\circ} 9.245 / 2017$, que estipulou como objetivos do Grupo, entre outros, a promoção da articulação entre órgãos e entidades públicas e setores da indústria e entidades voltados ao setor de saúde; e o fomento ao desenvolvimento industrial e tecnológico do CIS (BRASIL, 2017b).

Ainda, em 29 de maio, publica-se a Portaria Interministerial $\mathrm{n}^{\mathrm{o}} 128 / 2008$, estabelecendo diretrizes para a contratação pública de medicamentos e fármacos pelo SUS, em consonância com a política industrial vigente e a Lei 10.973/2004, reconhecendo o "caráter essencial dos famoquímicos e biofármacos como insumos para a fabricação de medicamentos e garantia da saúde e da vida". Essa portaria estabeleceu normas para compras de medicamentos e produção de fármacos, buscando ampliar o acesso da população a esse bem essencial e aumentar a eficiência produtiva (BRASIL, 2008c).

Faz-se necessário traçar um paralelo entre os esforços predominantes para fortalecimento do CEIS e a necessidade de adaptação e modificação de leis já existentes. A lei 8.666, de 1993, conhecida como a "lei de licitações", que regulamenta as compras e contratações realizadas pelas instituições da Administração Pública, assegurando que os princípios básicos da Administração Pública sejam cumpridos (legalidade, impessoalidade, moralidade, publicidade e eficiência), foi uma das que precisaram sofrer alterações para atender às prioridades estabelecidas pelo Governo em relação ao desenvolvimento industrial e econômico.

O artigo 24 da referida lei apresenta o rol de situações que ensejam a dispensa do processo licitatório, que são casos nos quais, geralmente, observa-se certa urgência ou emergência na aquisição de bens e serviços e outras situações especificadas na lei. Os incisos XXV, XXXI e XXXII abordam alguns casos que notadamente buscaram favorecer as atividades do SUS concernentes ao desenvolvimento científico e inovação, autorizando a dispensa de licitação para contratação realizada por ICT ou agência de fomento para a transferência de tecnologia e licenciamento de uso ou exploração de criação protegida, para contratação que vise o cumprimento dos art. $3^{\circ}, 4^{\circ}, 5^{\circ}$ e 20 da 
lei 10.973, de 2004, e na contratação em que há transferência tecnológica para o SUS, inclusive para compra de produtos durante esse processo de transferência, conforme instituído pela Lei 12715, de 2012 (BRASIL, 2004a; 2012b).

Foi durante a vigência do PBM que foram regulamentadas as PDPs, que são apontadas por alguns autores como uma das melhores estratégias no intuito de ampliar o acesso a medicamentos e produtos para a saúde considerados estratégicos para o SUS. Assim, em 2012, publicou-se a Portaria $\mathrm{n}^{\mathrm{o}} 506$, de 21 de março, a qual instituiu o Programa para o Desenvolvimento do Complexo Industrial da Saúde (PROCIS) e seu Comitê Gestor, com o objetivo geral de "fortalecer os produtores públicos e a infraestrutura de produção e inovação em saúde do setor público" (BRASIL, 2012c).

Pouco menos de um mês depois, em 18 de abril, é editada a Portaria $n^{\circ} 837$, definindo os critérios e diretrizes para o estabelecimento das PDP, caracterizando-as como

\begin{abstract}
parcerias realizadas entre instituições públicas e entidades privadas com vistas ao acesso a tecnologias prioritárias, à redução da vulnerabilidade do Sistema Único de Saúde (SUS) a longo prazo e à racionalização e redução de preços de produtos estratégicos para saúde, com o comprometimento de internalizar e desenvolver novas tecnologias estratégicas e de valor agregado elevado (BRASIL, 2012a).
\end{abstract}

Em 2017 foi promulgado o Decreto $n^{\circ}$ 9.245, que instituiu a Política Nacional de Inovação Tecnológica na Saúde (PNITS). As PDPs foram incluídas como um dos três instrumentos estratégicos da política. Nota-se assim certa perenidade das PDPs apesar das mudanças de mandatos no governo federal (BRASIL, 2017c).

Em novembro de 2014, as PDPs foram redefinidas por meio da Portaria $\mathrm{n}^{\mathrm{o}} 2.531$. Foram revistos os critérios para definição da lista de insumos estratégicos para o SUS, além de regulamentar a forma de apresentação de propostas e avaliação para novas parcerias. É nela que são apresentados os conceitos, os objetivos, a lista de produtos estratégicos e o processo para o estabelecimento de uma parceria, tornando o procedimento claro e redefinindo uma nova estratégia para a busca da inovação por meio da absorção e incorporação tecnológica, visando a subsistência do SUS sem a constante dependência do mercado externo (BRASIL, 2014)..

Em 2017, o Anexo XCV da Portaria de Consolidação GM/MS n 5/2017 incorporou as PDPs, apresentando-as como uma política que "visa ampliar o acesso a medicamentos e produtos para saúde considerados estratégicos para o Sistema Único de Saúde (SUS), por meio do fortalecimento do complexo industrial do país" (BRASIL, 2012; BRASIL, 2017). Ou seja, o intuito é garantir o acesso da população a produtos essenciais, além de agregar novas tecnologias e inovação ao parque produtivo nacional, mantendo o fomento do desenvolvimento tecnológico e o intercâmbio de conhecimentos.

$\mathrm{O}$ art. $3^{\circ}$ do Anexo XCV da Portaria ${ }^{\circ}$ 5/2017, apresenta quais são os objetivos das PDPs:

I - ampliar o acesso da população a produtos estratégicos e diminuir a vulnerabilidade do SUS;

II - reduzir as dependências produtiva e tecnológica para atender as necessidades de saúde da população brasileira a curto, médio e longo prazos, seguindo os princípios constitucionais do acesso universal e igualitário às ações e aos serviços de saúde;

III - racionalizar o poder de compra do Estado, mediante a centralização seletiva dos gastos na área da saúde, com vistas à sustentabilidade do SUS e à ampliação da produção no País de produtos estratégicos;

IV - proteger os interesses da Administração Pública e da sociedade ao buscar a economicidade e a vantajosidade, considerando-se preços, qualidade, tecnologia e benefícios sociais;

$\mathrm{V}$ - fomentar o desenvolvimento tecnológico e o intercâmbio de conhecimentos para a inovação no âmbito das instituições públicas e das entidades privadas, contribuindo para o desenvolvimento do CEIS e para torná-las competitivas e capacitadas; 
VI - promover o desenvolvimento e a fabricação em território nacional de produtos estratégicos para o SUS;

VII - buscar a sustentabilidade tecnológica e econômica do SUS a curto, médio e longo prazos, com promoção de condições estruturais para aumentar a capacidade produtiva e de inovação do País, contribuir para redução do déficit comercial do CEIS e garantir o acesso à saúde; e

VIII - estimular o desenvolvimento da rede de produção pública no País e do seu papel estratégico para o SUS (BRASIL, 2017).

Com relação ao processo das PDPs, o passo inicial é a divulgação de uma lista contendo os produtos estratégicos para o SUS, cuja elaboração é realizada pelo Grupo Executivo do Complexo Industrial da Saúde (GECIS/MS). Após lançamento da lista, dá-se início à execução das PDPs, que se divide em quatro fases, quais sejam (BRASIL, 2014): Fase I: submissão e análise de proposta de parceria, remetida por instituição pública, e celebração de Termo de Compromisso entre o Ministério da Saúde e as instituições públicas e privadas que tiveram suas propostas aprovadas; Fase II: início da implementação do plano de trabalho previsto na proposta aprovada e objeto do Termo de Compromisso; Fase III: início da execução do desenvolvimento do produto, transferência e absorção de tecnologia objeto da PDP, culminando na celebração de contrato de aquisição do produto entre Ministério da Saúde e instituição pública e; Fase IV: internalização da tecnologia por parte da instituição pública (do insumo farmacêutico ativo ou do componente tecnológico crítico). O resumo dessas etapas é apresentado na Figura 1.

Figura 1 - Etapas de uma Parceria para o Desenvolvimento Produtivo (PDP)

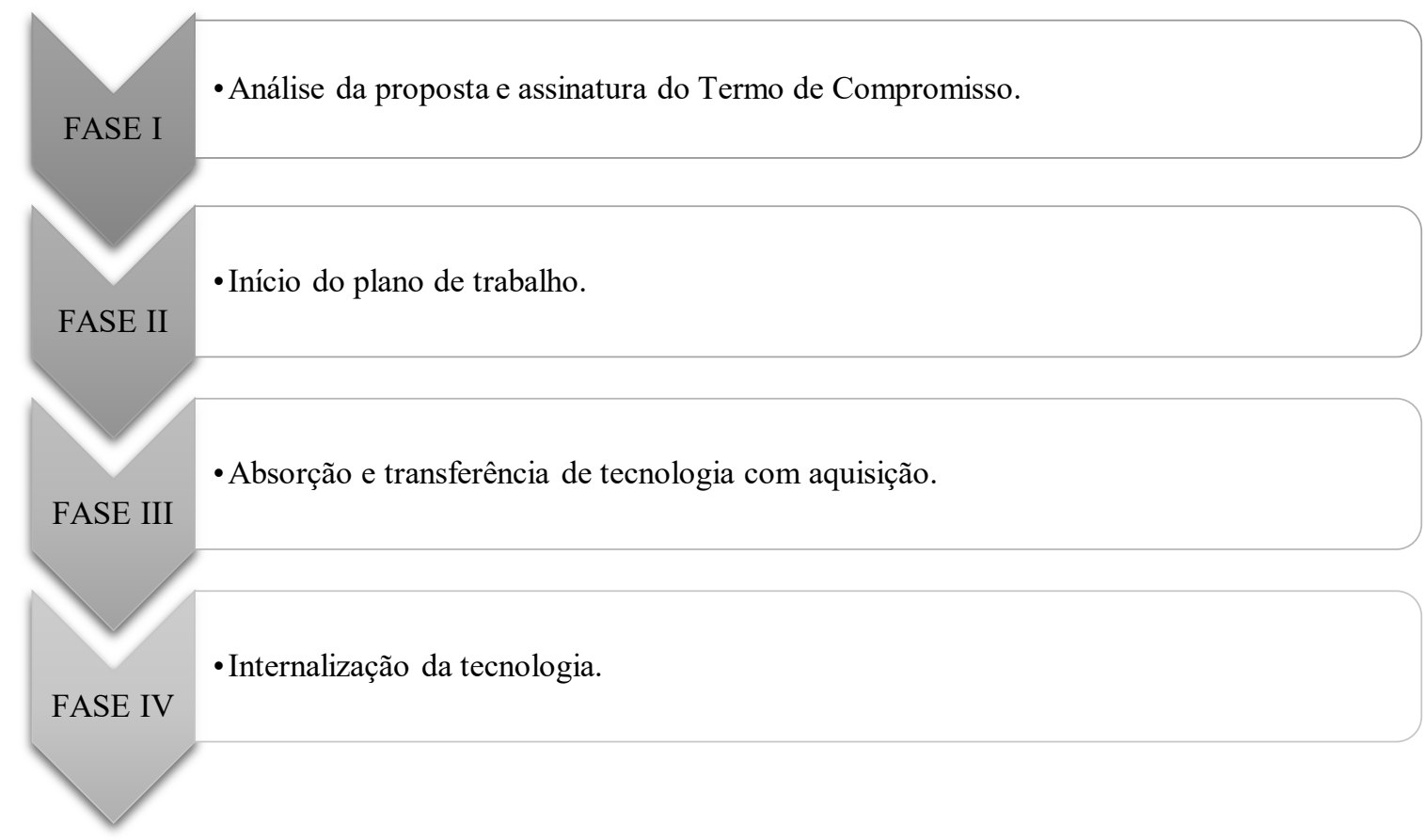

Fonte: Adaptado de Ministério da Saúde (2019).

Cabe ressaltar, ainda, que nas fases I e II não há ainda nenhuma ação concreta, sendo que a contagem de tempo da PDP inicia juntamente com a fase III e, para a conclusão da parceria, o prazo máximo estipulado é de dez anos. 
Importante destacar que, conforme aponta Almeida (2018), não necessariamente uma PDP passa automaticamente da fase II para a fase III, pois na fase II podem ocorrer entraves relacionados ao registro do produto, problemas com o deferimento da ANVISA, dificuldades na negociação de preço com o Ministério da Saúde, falta de consenso na definição das condições técnicas relacionadas à transferência, ou, inclusive, reprovação do registro. Nesse caso, ocorre a extinção da PDP.

Conforme informações do MS, cada PDP é monitorada continuamente, desde o início do projeto até a internalização da tecnologia, de maneira a verificar se os prazos, obrigações e responsabilidades estabelecidos estão, de fato, sendo cumpridos. Esse monitoramento é realizado pelo GECIS/MS conjuntamente com a Agência Nacional de Vigilância Sanitária (ANVISA), por meio dos Comitês Técnicos Regulatórios (CTR) coordenados pela agência (BRASIL, 2019).

No que concerne ao número de PDPs vigentes segundo fases do processo (desconsiderando as PDP suspensas), analisando os dados disponíveis pelo Ministério da Saúde, obtêm-se as seguintes informações (Tabela 1):

Tabela 1 - Número de PDPs vigentes por fase de projeto, Brasil, 2019.

\begin{tabular}{c|c|cc}
\hline Fase da PDP & $\begin{array}{c}\text { Medicamentos, vacinas e } \\
\text { hemoderivados }\end{array}$ & Produtos de saúde & Total \\
\hline Fase I & 8 & 0 & 8 \\
Fase II & 55 & 2 & 57 \\
Fase III & 20 & 3 & 23 \\
Fase IV & 9 & 0 & 9 \\
Total & $\mathbf{9 2}$ & $\mathbf{5}$ & $\mathbf{9 7}$ \\
\hline
\end{tabular}

Fonte: Elaboração própria com base nos dados do Ministério da Saúde (2019).

Nota: Dados atualizados pelos Ministério da Saúde em 17 jan. 2019 para produtos e em 29 mar. 2019.

Apesar do número total significativo, até a última atualização do MS, havia 32 parcerias que representam ação concreta (fases III e IV), mas não são 32 parcerias que correspondem, necessariamente, ao mesmo quantitativo de medicamentos e produtos, pois, para um mesmo item, pode haver mais de uma parceria. Estratégia essa que foi adotada para garantir abastecimento em determinados produtos, cujo volume de consumo pelo SUS é bastante elevado.

\section{Métodos da Pesquisa}

Em primeiro lugar, realizou-se uma coleta de dados relacionada aos produtos de saúde que possuem termos de compromisso assinados junto ao Ministério da Saúde e que já estão na fase III e IV das parcerias estabelecidas, sendo encontrados 29 medicamentos, vacinas e hemoderivados nessas fases, conforme dados já apresentados na Tabela 1. A partir disso, foi possível verificar o valor gasto com a compra de cada medicamento desde o início da vigência da fase III da PDP, assim como buscar dados que colaborassem para a realização de uma comparação em termos econômicos dos dispêndios realizados pelo Ministério da Saúde com a compra desses insumos considerados essenciais. 
Para fins de delimitação temporal, foram avaliadas as compras realizadas no período compreendido entre os anos de 2009 e 2018, considerando que a PDP vigente mais antiga data dessa época. As quantidades e valores gastos das compras realizadas via PDPs foram obtidos por meio do site do Ministério da Saúde, sendo que os dados foram atualizados em abril de 2019 pela Secretaria de Ciência, Tecnologia e Insumos Estratégicos (SCTIE).

E de maneira a realizar a comparação entre os gastos efetuados com os mesmos produtos de saúde antes da vigência das PDPs, foram avaliadas as compras e valores pagos em cada medicamento em um período de, no máximo, dois anos anteriores ao início da parceria, sendo que os dados foram obtidos por meio do portal de relatórios de gestão disponibilizados pela SCTIE anualmente desde 2008. Dos preços pagos, realizou-se uma média ponderada do período para fins de comparação.

Considerando o longo período avaliado e a importância de obter dados reais para fins de comparabilidade, a variação de preços obtidos na pesquisa foram comparados com a variação do Índice Nacional de Preços ao Consumidor (IPCA), para o mesmo período de referência. O uso desse índice deflacionário se baseia na Lei $\mathrm{n}^{\circ} 10.742 / 2003$, que, entre outras atribuições, define normas de regulação para o setor farmacêutico e estabelece em seu art. $4^{\circ}, \S 2^{\circ}$, que as empresas produtoras de medicamentos deverão observar, para fins de ajustes de preços de medicamentos, o Índice Nacional de Preços ao Consumidor". O IPCA é calculado anualmente pelo Instituto Brasileiro de Geografia e Estatística (IBGE), sendo divulgado diretamente pelo Instituto de Pesquisa Econômica Aplicada (IPEA). Esse índice objetiva "medir a inflação de um conjunto de produtos e serviços comercializados no varejo, referentes ao consumo pessoal das famílias, cujo rendimento varia entre 1 e 40 salários mínimos, qualquer que seja a fonte de rendimento" (IBGE, 2019).

No intuito de possibilitar uma verificação inicial concernente ao objetivo da redução de custo de aquisição, foram analisadas neste artigo as compras efetuadas entre os anos de 2008 e 2011 (anterior à assinatura do termo de compromisso das PDPs) relacionadas a 11 medicamentos com contratos vigentes e enquadrados na fase III, conforme resumido no Quadro 2.

Quadro 2 - Medicamentos analisados

\begin{tabular}{|c|c|c|}
\hline Produto & Laboratório público & Indicação terapêutica \\
\hline Atazanavir $200 \mathrm{mg}$ & Farmanguinhos & Antirretroviral \\
\hline Atazanavir 300mg & Farmanguinhos & Antirretroviral \\
\hline Betainterferona 1A 22mg & Biomanguinhos & Esclerose múltipla \\
\hline Betainterferona 1A 44mg & Biomanguinhos & Esclerose múltipla \\
\hline Everolimo $0,5 \mathrm{mg}$ & FURP & Câncer renal \\
\hline Everolimo $0,75 \mathrm{mg}$ & FURP & Câncer renal \\
\hline Everolimo 1mg & FURP & Câncer renal \\
\hline Infliximabe $10 \mathrm{mg}$ & Biomanguinhos & Doenças autoimunes \\
\hline Micofenolato de sódio $180 \mathrm{mg}$ & FURP & Imunossupressor \\
\hline Micofenolato de sódio $360 \mathrm{mg}$ & FURP & Imunossupressor \\
\hline Quetiapina $25 \mathrm{mg}$ & LAFEPE & Antipsicótico \\
\hline Quetiapina $100 \mathrm{mg}$ & LAFEPE & Antipsicótico \\
\hline Quetiapina 200mg & LAFEPE & Antipsicótico \\
\hline $\begin{array}{c}\text { Rifampicina + Isoniazida Pirazinamida + Etambutol } \\
(4 \text { em } 1 \text { Tuberculostático }) \\
(150 \mathrm{mg}+75 \mathrm{mg}+400 \mathrm{mg}+275 \mathrm{mg})\end{array}$ & Farmanguinhos & Tuberculose \\
\hline
\end{tabular}




\begin{tabular}{|c|c|c|}
\hline Produto & Laboratório público & Indicação terapêutica \\
\hline Sevelâmer $800 \mathrm{mg}$ & Bahifarma $(50 \%) /$ Farmanguinhos $(50 \%)$ & Doença renal \\
\hline Tacrolimo $1 \mathrm{mg}$ & Farmanguinhos & Imunossupressor \\
\hline Tacrolimo $5 \mathrm{mg}$ & Farmanguinhos & Imunossupressor \\
\hline Tenofovir 300mg & FUNED (50\%)/ LAFEPE (50\%) & Antirretroviral \\
\hline
\end{tabular}

Fonte: Elaboração própria com base nos dados do Ministério da Saúde (2019).

Os dados foram avaliados para permitir uma comparabilidade que torne possível realizar uma inferência inicial a respeito do suposto enfrentamento da dependência tecnológica do SUS por meio da um viés de economicidade. Os valores relacionados às compras realizadas antes do início da parceria foram obtidos por meio de relatórios publicados anualmente pela Secretaria de Ciência, Tecnologia e Insumos Estratégicos (SCTIE) do Ministério da Saúde. Os relatórios utilizados neste trabalho foram os de 2008 a 2011, por conterem dados mais completos relacionados às aquisições. Os relatórios de 2013 e 2014 não apresentaram dados discriminados sobre essas compras. Os dados referentes às compras após o início da vigência das PDPs foram obtidos por meio do sítio eletrônico do Ministério da Saúde, sendo que os quantitativos e valores foram atualizados em abril deste ano (2019) pela mesma SCTIE, optando-se por verificar as compras realizadas entre 2014 (marco regulatório mais consistente das PDPs) e 2017.

\section{Análise e Discussão dos Resultados}

A Tabela 2 apresenta os resultados da pesquisa de maneira individualizada. É importante ressaltar que esta forma de tabulação, embora exaustiva ao leitor, fez-se necessária. As unidades de medida dos diferentes medicamentos não são comparáveis, pois a forma de apresentação dos medicamentos pode ser distinta, isto é, em comprimidos, ampolas, frascos etc., bem como apresentar concentração distinta do princípio ativo. Assim, a avaliação da economicidade das compras só é possível produto a produto, uma vez que os preços e quantidades são heterogêneos.

Os dados da Tabela 2 trazem dois resultados interessantes das PDPs. O primeiro é que para maioria dos produtos, o preço de aquisição no período de 2014-2017, quando os produtos passam ser adquiridos por meio de dispensa de licitação, fruto do contrato de parceria para transferência de tecnologia ao SUS, se reduz em termos nominais. Logo, como a inflação do período foi positiva, não é preciso deflacionar a série para inferir que houve redução real no preço de aquisição desses medicamentos.

O segundo resultado refere-se ao aumento das quantidades de medicamentos adquiridas, denotando que, além do objetivo de redução de preços, ao menos nos casos analisados, a política tem contribuído também para a ampliação do acesso aos medicamentos no âmbito do SUS. Embora a redução de preço não se traduza em aumento das quantidades, indicando maior poder de compra do orçamento do Ministério, para todos os produtos analisados, pode-se afirmar que esta foi uma tendência, salvo casos específicos. Deve-se considerar, porém, que outros fatores são determinantes das quantidades adquiridas, sendo o tipo de doença e sua prevalência na população alguns deles. Logo, a redução dos preços de aquisição nem sempre se convertem, na mesma proporção, em aumentos de quantidades. 
Tabela 2 - Quantidade, valor de aquisição e valor unitário antes e após as PDPs

\begin{tabular}{|c|c|c|c|c|c|c|c|c|}
\hline \multirow[b]{2}{*}{ Medicamento } & \multicolumn{4}{|c|}{ Antes da PDP } & \multicolumn{4}{|c|}{ Pós-PDP } \\
\hline & Ano & Qtde. & Valor total (R\$) & $\begin{array}{l}\text { Valor un. } \\
\text { (R\$) }\end{array}$ & Ano & Qtde. & Valor total (R\$) & $\begin{array}{l}\text { Valor un. } \\
\text { (R\$) }\end{array}$ \\
\hline Atazanavir 200mg & $\begin{array}{l}2008 \\
2009 \\
2010 \\
2011\end{array}$ & $\begin{array}{l}14.400 .000 \\
2.004 .000 \\
6.975 .000\end{array}$ & $\begin{array}{l}61.108 .560 \\
10.470 .900 \\
30.194 .775\end{array}$ & $\begin{array}{l}4,24 \\
5,23 \\
- \\
4,33\end{array}$ & $\begin{array}{l}2014 \\
2015 \\
2016 \\
2017\end{array}$ & $\begin{array}{l}10.584 .840 \\
4.629 .420 \\
- \\
-\end{array}$ & $\begin{array}{l}36.760 .514 \\
15.415 .968\end{array}$ & 3,40 \\
\hline Atazanavir 300mg & $\begin{array}{l}2008 \\
2009 \\
2010 \\
2011\end{array}$ & $\begin{array}{l}4.125 .000 \\
8.970 .000 \\
19.800 .000\end{array}$ & $\begin{array}{l}35.970 .000 \\
90.148 .500 \\
108.108 .000\end{array}$ & $\begin{array}{l}8,72 \\
10,05 \\
- \\
5,46\end{array}$ & $\begin{array}{l}2014 \\
2015 \\
2016 \\
2017\end{array}$ & $\begin{array}{l}34.439 .070 \\
27.721 .740 \\
- \\
-\end{array}$ & $\begin{array}{l}194.723 .201 \\
151.360 .700\end{array}$ & $\begin{array}{l}5,65 \\
5,46 \\
-\end{array}$ \\
\hline Betainterferona 1A $22 \mathrm{mcg}$ & $\begin{array}{l}2008 \\
2009 \\
2010 \\
2011\end{array}$ & $\begin{array}{l}- \\
119.718 \\
142.579\end{array}$ & $\begin{array}{l}- \\
32.054 .494 \\
32.449 .554\end{array}$ & $\begin{array}{l}- \\
267,75 \\
227,60\end{array}$ & $\begin{array}{l}2014 \\
2015 \\
2016 \\
2017\end{array}$ & $\begin{array}{l}150.240 \\
179.280 \\
132.384\end{array}$ & $\begin{array}{l}20.172 .724 \\
23.589 .662 \\
16.767 .757\end{array}$ & $\begin{array}{l}- \\
134,27 \\
131,58 \\
126,66\end{array}$ \\
\hline Betainterferona 1A 44mcg & $\begin{array}{l}2008 \\
2009 \\
2010 \\
2011\end{array}$ & $\begin{array}{l}- \\
243.714 \\
287.699\end{array}$ & $\begin{array}{l}75.916 .911 \\
76.176 .941\end{array}$ & $\begin{array}{l}- \\
311,50 \\
264,78\end{array}$ & $\begin{array}{l}2014 \\
2015 \\
2016 \\
2017\end{array}$ & $\begin{array}{l}422.292 \\
433.464 \\
405.168\end{array}$ & $\begin{array}{l}64.019 .467 \\
64.399 .746 \\
57.939 .024\end{array}$ & $\begin{array}{l}- \\
151,60 \\
148,57 \\
143,00\end{array}$ \\
\hline Everolimo $0,5 \mathrm{mg}$ & $\begin{array}{l}2008 \\
2009 \\
2010 \\
2011\end{array}$ & $\begin{array}{l}- \\
204.060 \\
460.213\end{array}$ & $\begin{array}{l}- \\
1.669 .210 \\
3.677 .101\end{array}$ & $\begin{array}{l}- \\
8,18 \\
7,99\end{array}$ & $\begin{array}{l}2014 \\
2015 \\
2016 \\
2017\end{array}$ & $\begin{array}{l}1.269 .540 \\
317.340 \\
-\end{array}$ & $\begin{array}{l}8.163 .142 \\
2.040 .972\end{array}$ & $\begin{array}{l}6,43 \\
6,43 \\
-\end{array}$ \\
\hline Everolimo $0,75 \mathrm{mg}$ & $\begin{array}{l}2008 \\
2009 \\
2010 \\
2011\end{array}$ & $\begin{array}{l}- \\
192.120 \\
261.447\end{array}$ & $\begin{array}{l}- \\
2.357 .312 \\
3.134 .749\end{array}$ & $\begin{array}{l}- \\
12,27 \\
11,99\end{array}$ & $\begin{array}{l}2014 \\
2015 \\
2016 \\
2017\end{array}$ & $\begin{array}{l}1.108 .140 \\
277.020 \\
-\end{array}$ & $\begin{array}{l}10.693 .551 \\
2.673 .797 \\
-\end{array}$ & 9,65 \\
\hline Everolimo 1mg & $\begin{array}{l}2008 \\
2009 \\
2010 \\
2011\end{array}$ & $\begin{array}{l}- \\
180.180 \\
423.234\end{array}$ & $\begin{array}{l}- \\
2.947 .744 \\
6.763 .279\end{array}$ & $\begin{array}{l}- \\
- \\
16,36 \\
15,98\end{array}$ & $\begin{array}{l}2014 \\
2015 \\
2016 \\
2017\end{array}$ & $\begin{array}{l}2.348 .580 \\
587.100 \\
- \\
-\end{array}$ & $\begin{array}{l}30.202 .739 \\
7.551 .867\end{array}$ & $\begin{array}{l}12,86 \\
12,86 \\
-\end{array}$ \\
\hline Infliximabe $10 \mathrm{mg}$ & $\begin{array}{l}2008 \\
2009 \\
2010 \\
2011\end{array}$ & $\begin{array}{l}- \\
97.893 \\
161.171\end{array}$ & $\begin{array}{l}144.881 .640 \\
196.628 .620\end{array}$ & $\begin{array}{l}- \\
1.480,00 \\
1.220,00\end{array}$ & $\begin{array}{l}2014 \\
2015 \\
2016 \\
2017\end{array}$ & $\begin{array}{l}178.969 \\
44.743 \\
689.973 \\
281.290\end{array}$ & $\begin{array}{l}164.715 .908 \\
41.179 .667 \\
628.426 .676 \\
248.134 .347\end{array}$ & $\begin{array}{l}920,36 \\
920,36 \\
910,80 \\
882,13\end{array}$ \\
\hline Micofenolatode sódio $180 \mathrm{mg}$ & $\begin{array}{l}2008 \\
2009 \\
2010 \\
2011\end{array}$ & $\begin{array}{l}- \\
1.573 .680 \\
2.204 .824\end{array}$ & $\begin{array}{l}- \\
4.815 .460 \\
6.283 .748\end{array}$ & $\begin{array}{l}- \\
3,06 \\
2,85\end{array}$ & $\begin{array}{l}2014 \\
2015 \\
2016 \\
2017\end{array}$ & $\begin{array}{l}3.887 .040 \\
4.024 .800 \\
- \\
-\end{array}$ & $\begin{array}{l}9.068 .464 \\
8.920 .566 \\
- \\
-\end{array}$ & 2,33 \\
\hline
\end{tabular}




\begin{tabular}{|c|c|c|c|c|c|c|c|c|}
\hline \multirow[b]{2}{*}{ Medicamento } & \multicolumn{4}{|c|}{ Antes da PDP } & \multicolumn{4}{|c|}{ Pós-PDP } \\
\hline & Ano & Qtde. & Valor total (R\$) & $\begin{array}{l}\text { Valor un. } \\
\text { (R\$) }\end{array}$ & Ano & Qtde. & Valor total (R\$) & $\begin{array}{l}\text { Valor un. } \\
\text { (R\$) }\end{array}$ \\
\hline Micofenolatode sódio $360 \mathrm{mg}$ & $\begin{array}{l}2008 \\
2009 \\
2010 \\
2011\end{array}$ & $\begin{array}{l}- \\
15.423 .720 \\
21.142 .406\end{array}$ & $\begin{array}{l}94.393 .166 \\
120.511 .714\end{array}$ & $\begin{array}{l}- \\
6,12 \\
5,70\end{array}$ & $\begin{array}{l}2014 \\
2015 \\
2016 \\
2017\end{array}$ & $\begin{array}{l}41.352 .840 \\
39.574 .800 \\
-\end{array}$ & $\begin{array}{l}198.721 .072 \\
180.666 .876 \\
-\end{array}$ & $\begin{array}{l}4,81 \\
4,56 \\
- \\
-\end{array}$ \\
\hline Quetiapina 25mg & $\begin{array}{l}2008 \\
2009 \\
2010 \\
2011\end{array}$ & $\begin{array}{l}- \\
- \\
1.673 .980\end{array}$ & - & $\begin{array}{l}- \\
- \\
0,90\end{array}$ & $\begin{array}{l}2014 \\
2015 \\
2016 \\
2017\end{array}$ & $\begin{array}{l}13.819 .624 \\
14.779 .380 \\
18.140 .700\end{array}$ & $\begin{array}{l}9.397 .344 \\
9.547 .479 \\
10.547 .002\end{array}$ & $\begin{array}{l}0,68 \\
0,65 \\
0,58 \\
-\end{array}$ \\
\hline Quetiapina 100mg & $\begin{array}{l}2008 \\
2009 \\
2010 \\
2011\end{array}$ & $\begin{array}{l}- \\
- \\
2.318 .636\end{array}$ & - & $\begin{array}{l}- \\
- \\
3,07\end{array}$ & $\begin{array}{l}2014 \\
2015 \\
2016 \\
2017\end{array}$ & $\begin{array}{l}18.105 .640 \\
19.305 .870 \\
21.897 .300\end{array}$ & $\begin{array}{l}28.969 .024 \\
29.344 .922 \\
29.955 .506\end{array}$ & $\begin{array}{l}1,60 \\
1,52 \\
1,37 \\
-\end{array}$ \\
\hline Quetiapina 200mg & $\begin{array}{l}2008 \\
2009 \\
2010 \\
2011\end{array}$ & $\begin{array}{l}- \\
- \\
3.046 .624\end{array}$ & - & $\begin{array}{l}- \\
- \\
5,51\end{array}$ & $\begin{array}{l}2014 \\
2015 \\
2016 \\
2017\end{array}$ & $\begin{array}{l}17.000 .424 \\
18.292 .980 \\
15.307 .860\end{array}$ & $\begin{array}{l}61.371 .530 \\
62.744 .921 \\
47.255 .363\end{array}$ & $\begin{array}{l}3,61 \\
3,43 \\
3,09 \\
-\end{array}$ \\
\hline $\begin{array}{l}\text { Rifampicina + Isoniazida } \\
\text { + Pirazinamida + Etambutol ( } 4 \\
\text { em } 1 \text { Tuberculostático) } \\
(150 \mathrm{mg}+75 \mathrm{mg}+400 \mathrm{mg}+275 \mathrm{mg})\end{array}$ & $\begin{array}{l}2008 \\
2009 \\
2010 \\
2011\end{array}$ & $\begin{array}{l}40.320 .000 \\
- \\
19.500 .000\end{array}$ & $\begin{array}{l}5.068 .256 \\
1.947 .057\end{array}$ & $\begin{array}{l}- \\
0,13 \\
0,10\end{array}$ & $\begin{array}{l}2014 \\
2015 \\
2016 \\
2017\end{array}$ & 24.000 .480 & 9.157 .863 & 0,38 \\
\hline Sevelâmer $800 \mathrm{mg}$ & $\begin{array}{l}2008 \\
2009 \\
2010 \\
2011\end{array}$ & $\begin{array}{l}41.729 .040 \\
41.729 .040 \\
52.804 .629\end{array}$ & $\begin{array}{l}37.489 .369 \\
37.489 .369 \\
42.190 .898\end{array}$ & $\begin{array}{l}- \\
0,90 \\
0,90 \\
0,80\end{array}$ & $\begin{array}{l}2014 \\
2015 \\
2016 \\
2017\end{array}$ & $\begin{array}{l}68.930 .100 \\
75.626 .640 \\
77.716 .080\end{array}$ & $\begin{array}{l}77.201 .712 \\
82.433 .036 \\
80.047 .562\end{array}$ & $\begin{array}{l}1,12 \\
1,09 \\
1,03\end{array}$ \\
\hline Tacrolimo 1mg & $\begin{array}{l}2008 \\
2009 \\
2010 \\
2011\end{array}$ & $\begin{array}{l}- \\
24.079 .300 \\
33.402 .061\end{array}$ & $\begin{array}{l}8 \\
88.973 .013 \\
105.216 .492\end{array}$ & $\begin{array}{l}- \\
3,69 \\
3,15\end{array}$ & $\begin{array}{l}2014 \\
2015 \\
2016 \\
2017\end{array}$ & $\begin{array}{l}55.357 .300 \\
64.119 .400\end{array}$ & $\begin{array}{l}126.214 .644 \\
139.139 .098\end{array}$ & $\begin{array}{l}- \\
2,28 \\
2,17\end{array}$ \\
\hline Tacrolimo 5mg & $\begin{array}{l}2008 \\
2009 \\
2010 \\
2011\end{array}$ & $\begin{array}{l}- \\
1.550 .375 \\
1.790 .578\end{array}$ & $\begin{array}{l}- \\
27.503 .652 \\
27.431 .296\end{array}$ & $\begin{array}{l}- \\
- \\
17,74 \\
15,32\end{array}$ & $\begin{array}{l}2014 \\
2015 \\
2016 \\
2017\end{array}$ & $\begin{array}{l}3.259 .650 \\
4.532 .400 \\
-\end{array}$ & $\begin{array}{l}36.410 .290 \\
48.088 .764\end{array}$ & $\begin{array}{l}- \\
11,17 \\
10,61 \\
-\end{array}$ \\
\hline Tenofovir 300mg & $\begin{array}{l}2008 \\
2009 \\
2010 \\
2011\end{array}$ & $\mid \begin{array}{l}11.400 .000 \\
18.000 .000 \\
30.000 .000 \\
36.000 .000\end{array}$ & $\begin{array}{l}73.515 .000 \\
114.300 .000 \\
120.750 .000 \\
144.720 .000\end{array}$ & $\begin{array}{l}6,45 \\
6,35 \\
4,03 \\
4,02\end{array}$ & $\begin{array}{l}2014 \\
2015 \\
2016 \\
2017\end{array}$ & $\begin{array}{l}24.000 .000 \\
9.990 .000 \\
-\end{array}$ & $\begin{array}{l}87.072 .000 \\
34.431 .534 \\
-\end{array}$ & $\begin{array}{l}3,63 \\
3,45 \\
-\end{array}$ \\
\hline
\end{tabular}

Fonte: Elaboração própria. 
Conforme pode ser observado na Tabela 2, nem todos os medicamentos foram adquiridos em todos os anos. A Quetiapina, por exemplo, começou a ser adquirida no ano de $2011 \mathrm{e}$, nesse mesmo ano, foi adquirida tanto por meio de importação, quanto pelo convênio de PDP nº. 19/2011. Ambas as aquisições ocorreram pelo mesmo preço (R \$ 5,51). O medicamento sevelâmer possui duas PDPs vigentes desde 2016, sendo que a aquisição é dividida meio a meio entre os dois laboratórios responsáveis. Os valores da Tabela 2 correspondentes aos anos de 2016 e 2017 representam a soma das duas instituições.

De maneira a possibilitar uma melhor visualização concernente às aquisições e diferença de preços, a Tabela 3 apresenta a média de preços de cada medicamento nos períodos pré e pós-PDPs (2008 a 2011 e 2014 a 2017, respectivamente), bem como o percentual de variação entre os períodos.

Nota-se que do período analisado, apenas os medicamentos Rifampicina + Isoniazida + Pirazinamida + Etambutol (4 em 1 Tuberculostático) (150mg+75mg+400mg+275mg) e sevelâmer sofreram aumento nos preços nominais após a vigência das PDPs. Considerando que a inflação acumulada no período de 2008, medido pelo IPCA, foi de $24,6 \%$, e no período de 2014-2017 foi de $28,9 \%$, nota-se que no primeiro caso, o reajuste médio dos preços dos medicamentos na compra via PDP foi da ordem de $217 \%$, bem superior ao IPCA. Já no segundo caso, apesar do aumento do preço nominal estar próximo ao do IPCA, pode-se considerar que seu preço real diminuiu levemente, quando a compra foi realizada por meio de PDP.

Tabela 3 - Variação dos preços médios pré e pós-PDPs das aquisições de medicamentos

\begin{tabular}{|c|c|c|c|}
\hline Medicamento & $\begin{array}{c}\text { Preço médio } \\
\text { pré-PDPs }\end{array}$ & $\begin{array}{c}\text { Preço médio } \\
\text { pós-PDPs }\end{array}$ & Variação (\%) \\
\hline Atazanavir $200 \mathrm{mg}$ & 4,60 & 3,37 & $(26,74)$ \\
\hline Atazanavir 300mg & 8,08 & 5,56 & $(31,19)$ \\
\hline Betainterferona 1A $22 \mathrm{mcg}$ & 247,68 & 130,84 & $(54,59)$ \\
\hline Betainterferona $1^{\mathrm{a}} 44 \mathrm{mcg}$ & 288,14 & 147,72 & $(48,73)$ \\
\hline Everolimo $0,5 \mathrm{mg}$ & 8,09 & 6,43 & $(20,52)$ \\
\hline Everolimo $0,75 \mathrm{mg}$ & 12,13 & 9,65 & $(20,45)$ \\
\hline Everolimo 1mg & 16,17 & 12,86 & $(20,47)$ \\
\hline Infliximabe $10 \mathrm{mg}$ & $1.350,00$ & 908,41 & $(32,71)$ \\
\hline Micofenolatode sódio $180 \mathrm{mg}$ & 2,96 & 2,28 & $(22,97)$ \\
\hline Micofenolatode sódio $360 \mathrm{mg}$ & 5,91 & 4,69 & $(20,64)$ \\
\hline Quetiapina $25 \mathrm{mg}$ & 0,90 & 0,64 & $(28,89)$ \\
\hline Quetiapina 100mg & 3,07 & 1,50 & $(51,14)$ \\
\hline Quetiapina 200mg & 5,51 & 3,38 & $(38,66)$ \\
\hline $\begin{array}{l}\text { Rifampicina + Isoniazida + Pirazinamida } \\
\text { Etambutol (4 em } 1 \text { Tuberculostático }) \\
\text { (150mg+75mg+400mg+275mg) }\end{array}$ & 0,12 & 0,38 & 216,67 \\
\hline Sevelâmer $800 \mathrm{mg}$ & 0,87 & 1,08 & 24,14 \\
\hline Tacrolimo $1 \mathrm{mg}$ & 3,42 & 2,23 & $(34,80)$ \\
\hline Tacrolimo $5 \mathrm{mg}$ & 16,53 & 10,89 & $(34,12)$ \\
\hline Tenofovir 300mg & 5,21 & 3,54 & $(32,05)$ \\
\hline
\end{tabular}


De maneira análoga à Tabela 3, a Tabela 4 apresenta uma síntese das variações nas quantidades adquiridas, por produto. Nela são apresentadas as quantidades médias anuais de medicamentos adquiridos no período pré e pós-PDPs, bem como a variação percentual nas médias entre os períodos.

Tabela 4 - Variação das quantidades médias anuais de medicamentos adquiridos pré e pós-PDPs

\begin{tabular}{|c|c|c|c|}
\hline Medicamento & $\begin{array}{c}\text { Quantidade média } \\
\text { pré-PDPs }\end{array}$ & $\begin{array}{c}\text { Quantidade média } \\
\text { pós-PDPs }\end{array}$ & Variação (\%) \\
\hline Atazanavir $200 \mathrm{mg}$ & 7.793 .000 & 7.607 .130 & $(2,4 \%)$ \\
\hline Atazanavir $300 \mathrm{mg}$ & 10.965 .000 & 31.080 .405 & $183,5 \%$ \\
\hline Betainterferona 1A 22mcg & 131.149 & 150.240 & $14,6 \%$ \\
\hline Betainterferona $1^{\mathrm{a}} 44 \mathrm{mcg}$ & 265.707 & 422.292 & $58,9 \%$ \\
\hline Everolimo $0,5 \mathrm{mg}$ & 332.137 & 793.440 & $138,9 \%$ \\
\hline Everolimo $0,75 \mathrm{mg}$ & 226.784 & 692.580 & $205,4 \%$ \\
\hline Everolimo 1mg & 301.707 & 1.467 .840 & $386,5 \%$ \\
\hline Infliximabe $10 \mathrm{mg}$ & 129.532 & 111.856 & $(13,6 \%)$ \\
\hline Micofenolatode sódio $180 \mathrm{mg}$ & 1.889 .252 & 3.955 .920 & $109,4 \%$ \\
\hline Micofenolatode sódio $360 \mathrm{mg}$ & 18.283 .063 & 40.463 .820 & $121,3 \%$ \\
\hline Quetiapina 25mg & 1.673 .980 & 14.299 .502 & $754,2 \%$ \\
\hline Quetiapina 100mg & 2.318 .636 & 18.705 .755 & $706,8 \%$ \\
\hline Quetiapina 200mg & 3.046 .624 & 17.646 .702 & $479,2 \%$ \\
\hline $\begin{array}{c}\text { Rifampicina + Isoniazida + Pirazinamida } \\
\text { Etambutol (4 em } 1 \text { Tuberculostático) } \\
(150 \mathrm{mg}+75 \mathrm{mg}+400 \mathrm{mg}+275 \mathrm{mg})\end{array}$ & 29.910 .000 & 24.000 .480 & $(19,8 \%)$ \\
\hline Sevelâmer $800 \mathrm{mg}$ & 45.420 .903 & 68.930 .100 & $51,8 \%$ \\
\hline Tacrolimo 1mg & 28.740 .681 & 55.357 .300 & $92,6 \%$ \\
\hline Tacrolimo 5mg & 1.670 .477 & 3.259 .650 & $95,1 \%$ \\
\hline Tenofovir 300mg & 23.850 .000 & 16.995 .000 & $(28,7 \%)$ \\
\hline
\end{tabular}

Fonte: Elaboração própria.

Em que pese a redução dos preços de aquisição dos medicamentos ter sido de até $55 \%$, conforme os dados da Tabela 3, verifica-se que o volume médio adquirido para alguns desses produtos chegou a elevar até $755 \%$, como foi o caso da Quetiapina $25 \mathrm{mg}$, cuja redução média de preços foi de $29 \%$. Para a maioria dos produtos analisados, o aumento nas quantidades adquiridas pelo Ministério da Saúde foi mais do que proporcional à redução nos preços.

Além de representar economicidade para a administração pública e ampliação da capacidade de oferta da assistência farmacêutica no âmbito do SUS, a política tem como contrapartida a geração de receita aos laboratórios da rede oficial. O valor do faturamento a esses laboratórios, conforme dados da Tabela 2, variou de 2 a 628 milhões de reais por ano. Considerando que muitos dos 
laboratórios dependem do orçamento do ente da federação ao qual está vinculado, isso representa ainda um caminho para a autonomia financeira dos laboratórios públicos.

\section{Conclusões}

A combinação de instrumentos de política industrial faz das PDPs um caso curioso de ação do governo federal. Pensada de maneira sistêmica, as parcerias foram articuladas para atingir múltiplos propósitos. A análise dos resultados multifacetados dessa política está além do escopo deste artigo. Porém, foi possível observar, de maneira preliminar, que nos onze medicamentos analisados, em dezoito formas de apresentação, em apenas dois casos não foi verificada a economicidade esperada da política, o que denota, até o momento, uma taxa de sucesso bastante satisfatória.

Os resultados desta pesquisa, que comparou as compras públicas realizadas no período de 2008 a 2011 de onze medicamentos estratégicos do SUS com as compras posteriores à oficialização das parcerias, no período de 2015 a 2017, mostraram redução média de 20 a 55\% nos preços nominais, salvo dois casos específicos: tuberculostático (4 em 1) e Sevelâmer. Por outro lado, a quantidade apresentou aumento de $15 \%$ a $754 \%$ nas médias anuais após as PDPs, com poucas exceções em que a quantidade demandada pelo Ministério da Saúde retraiu. Além de representar economia orçamentária e ampliação da capacidade de oferta da assistência farmacêutica no âmbito do SUS, a política tem contribuído, ainda, para a autonomia financeira dos laboratórios da rede oficial, que foram sucateados ao longo das décadas de 1980 e 1990.

Alguns aspectos, porém, ficam em aberto para uma avaliação mais profunda da política. Há de fato vantajosidade para a administração pública oriunda da tecnologia incorporada e dos seus benefícios sociais? A resposta certamente não será unívoca, pois ela também tem de ser obtida de maneira individualizada por produto incorporado ao SUS. A eficácia, a segurança e o horizonte tecnológico de terapias alternativas em desenvolvimento no Brasil e no exterior determinarão uma resposta mais adequada a essa questão. Além disso, uma análise atualizada do aumento da competência tecnológica dos laboratórios públicos e privados nacionais e da superação da dependência tecnológica também deve ser conduzida em estudos futuros.

\section{Referências}

AITH, Fernando; BUJDOSO, Yasmim; NASCIMENTO, Paulo Roberto do; DALLARI, Sueli Gandolfi. Os princípios da universalidade e integralidade do sus sob a perspectiva da política de doenças raras e da incorporação tecnológica. R. Dir. sanit., São Paulo v.15 n.1, p. 10-39, mar./jun. 2014.

ALMEIDA, Águida Cristina Santos. Análise dos efeitos das parcerias para o desenvolvimento produtivo nos laboratórios farmacêuticos oficiais. 2018. 318 p. Tese (doutorado) - Universidade Federal do Rio de Janeiro, Instituto de Economia, Programa de Pós-Graduação em Economia da Indústria e da Tecnologia. Rio de Janeiro: 2018.

ARAÚJO JUNIOR, José Tavares de. O enigma da política industrial no Brasil. Revista de Economia Política, vol. 35, $\mathrm{n}^{\mathrm{o}} 3$ (140), pp. 461-474, julho-setembro/2015. Disponível em: http://www.scielo.br/scielo.php?script=sci_arttext\&pid=S0101-31572015000300461. Acesso em: 20 mar. 2019. 
BRASIL. Constituição da República Federativa do Brasil. Brasília: Supremo Tribunal Federal, Secretaria de Documentação, 1988.

BRASIL. Lei $\mathrm{n}^{0}$ 8.080, de 19 de setembro de 1990. Dispõe sobre as condições para promoção, proteção e recuperação da saúde, a organização e o funcionamento dos serviços correspondentes e dá outras providências. $\quad$ Brasília, $1990 . \quad$ Disponível em: http://www.planalto.gov.br/ccivil_03/leis/L8080.htm. Acesso em: 25 mai. 2019.

BRASIL. Ministério da Saúde. Secretaria de Políticas de Saúde. Departamento de Atenção Básica. Política nacional de medicamentos 2001/Ministério da Saúde, Secretaria de Políticas de Saúde, Departamento de Atenção Básica. - Brasília: Ministério da Saúde, 2001.

BRASIL. Lei $\mathrm{n}^{\circ} .10 .973$, de 02 de dezembro de 2004. Dispõe sobre incentivos à inovação e à pesquisa científica e tecnológica no ambiente produtivo e dá outras providências. Brasília, 2004a. Disponível em: http://www.planalto.gov.br/ccivil_03/_ato2004-2006/2004/lei/110.973.htm. Acesso em: $1^{\circ}$ jun. 2019.

BRASIL. Ministério da Saúde. Conselho Nacional de Saúde. Resolução nº 338, de 06 de maio de 2004. Política Nacional de Assistência Farmacêutica. Brasília, 2004b. Disponível em: http://bvsms.saude.gov.br/bvs/saudelegis/cns/2004/res0338_06_05_2004.html. Acesso em: $1^{\circ}$ jun. 2019.

BRASIL. Ministério da Saúde. Portaria $n^{\circ}$ 374, de 28 de fevereiro de 2008. Institui no âmbito do Sistema Único de Saúde - SUS, o Programa Nacional de Fomento à Produção Pública e Inovação no Complexo Industrial da Saúde. Brasília, 2008a. Disponível em: http://bvsms.saude.gov.br/bvs/saudelegis/gm/2008/prt0374_28_02_2008.html. Acesso em: 24 mai. 2019.

BRASIL. Decreto de 12 de maio de 2008. Cria, no âmbito do Ministério da Saúde, o Grupo Executivo do Complexo Industrial da Saúde- GECIS, e dá outras providências. Revogado pelo Decreto $\mathrm{n}^{\circ}$ 9.245, de 2017. Brasília, 2008b. Disponível em: http:/www.planalto.gov.br/ccivil_03/_Ato20072010/2008/Dnn/Dnn11578.htm. Acesso em: 24 mai. 2019.

BRASIL. Portaria Interministerial $\mathrm{n}^{\mathrm{o}}$. 128, de 29 de maio de 2008. Estabelece Diretrizes para a Contratação Pública de Medicamentos e Fármacos pelo Sistema Único de Saúde. Disponível em: http://www.comprasnet.gov.br/legislacao/portarias/p128_08.htm. Acesso em: 28 mai. 2019.

BRASIL. Decreto n ${ }^{\circ}$ 7.540, de 02 de agosto de 2011. Institui o Plano Brasil Maior - PBM e cria o seu Sistema de Gestão. Brasília, 2011. Disponível em: https://www.planalto.gov.br/ccivil_03/_ato2011-2014/2011/decreto/d7540.htm. Acesso em: 24 mai. 2019.

BRASIL. Ministério da Saúde. Gabinete do Ministro. Portaria n ${ }^{\circ} 837$, de 18 de abril de 2012: Define as diretrizes e os critérios para o estabelecimento das parcerias para o desenvolvimento produtivo (PDP). Brasília, 2012a. Disponível em: http://bvsms.saude.gov.br/bvs/saudelegis/gm/2012/prt0837_18_04_2012.html. Acesso em: 28 mai. 2019.

BRASIL. Lei $\mathrm{n}^{\mathrm{o}}$. 12.715, de 17 de setembro de 2012. Altera a alíquota das contribuições previdenciárias sobre a folha de salários devidas pelas empresas que especifica; institui o Programa de Incentivo à Inovação Tecnológica e Adensamento da Cadeia Produtiva de Veículos Automotores, o Regime Especial de Tributação do Programa Nacional de Banda Larga para Implantação de Redes de Telecomunicações, o Regime Especial de Incentivo a Computadores para Uso Educacional, o Programa Nacional de Apoio à Atenção Oncológica e o Programa Nacional de Apoio à Atenção da 
Saúde da Pessoa com Deficiência; restabelece o Programa Um Computador por Aluno; altera o Programa de Apoio ao Desenvolvimento Tecnológico da Indústria de Semicondutores, instituído pela Lei $\mathrm{n}^{\mathrm{o}}$ 11.484, de 31 de maio de 2007; altera as Leis $\mathrm{n}^{\mathrm{o}} \mathrm{s}$ 9.250, de 26 de dezembro de 1995, 11.033, de 21 de dezembro de 2004, 9.430, de 27 de dezembro de 1996, 10.865, de 30 de abril de 2004, 11.774, de 17 de setembro de 2008, 12.546, de 14 de dezembro de 2011, 11.484, de 31 de maio de 2007, 10.637, de 30 de dezembro de 2002, 11.196, de 21 de novembro de 2005, 10.406, de 10 de janeiro de 2002, 9.532, de 10 de dezembro de 1997, 12.431, de 24 de junho de 2011, 12.414, de 9 de junho de 2011, 8.666, de 21 de junho de 1993, 10.925, de 23 de julho de 2004, os Decretos-Leis $n^{\circ} \mathrm{s}$ 1.455, de 7 de abril de 1976, 1.593, de 21 de dezembro de 1977, e a Medida Provisória n 2.199-14, de 24 de agosto de 2001; e dá outras providências. Brasília, 2012b. Disponível em: http://www.planalto.gov.br/ccivil_03/_Ato2011-2014/2012/Lei/L12715.htm. Acesso em: 09 jun. 2019.

BRASIL. Ministério da Saúde. Portaria $\mathrm{n}^{0}$ 506, de 21 de março de 2012. Institui o Programa para o Desenvolvimento do Complexo Industrial da Saúde (PROCIS) e seu Comitê Gestor. Brasília, 2012c. Disponível em: http://bvsms.saude.gov.br/bvs/saudelegis/gm/2012/prt0506_21_03_2012.html. Acesso em: Acesso em: $1^{\mathrm{o}}$ jun. 2019.

BRASIL. Ministério da Saúde. Portaria nº. 2.531, de 12 de novembro de 2014. Redefine as diretrizes e os critérios para a definição da lista de produtos estratégicos para o Sistema Único de Saúde (SUS) e o estabelecimento das Parcerias para o Desenvolvimento Produtivo (PDP) e disciplina os respectivos processos de submissão, instrução, decisão, transferência e absorção de tecnologia, aquisição de produtos estratégicos para o SUS no âmbito das PDP e o respectivo monitoramento e avaliação. $\quad$ Brasília, 2014. Disponível em: http://bvsms.saude.gov.br/bvs/saudelegis/gm/2014/prt2531_12_11_2014.html. Acesso em: 21 mai. 2019.

BRASIL. Ministério da Saúde. Portaria de Consolidação GM/MS nº 5/2017. Consolidação das normas sobre as ações e os serviços de saúde do Sistema Único de Saúde. Anexo XCV. Dos critérios para a definição da lista de produtos estratégicos para o SUS e do estabelecimento das parcerias para o desenvolvimento produtivo (PDP) e dos respectivos processos de submissão, instrução, decisão, transferência e absorção de tecnologia, aquisição de produtos estratégicos para o SUS no âmbito das PDP e o respectivo monitoramento e avaliação. Brasília, 2017a. Disponível em: http://bvsms.saude.gov.br/bvs/saudelegis/gm/2017/prc0005_03_10_2017.html. Acesso em: 2 jun. 2019.

BRASIL. Casa Civil. Decreto nº 9.245, de 20 de dezembro de 2017.

Institui a Política Nacional de Inovação Tecnológica na Saúde. Brasília, 2017b. Disponível em: http://www.planalto.gov.br/ccivil_03/_ato2015-2018/2017/decreto/d9245.htm. Acesso em: 09 jun. 2019.

BRASIL. Ministério da Saúde. Parcerias para o Desenvolvimento Produtivo. Disponível em: http://www.saude.gov.br/saude-de-a-z/parcerias-para-o-desenvolvimento-produtivo-pdp. Acesso em: 09 jun. 2019.

CORONEL, D. A.; CAMPOS, A. C.; AZEVEDO, A. F. Z.; CARVAlHO, F. M. A. Impactos da política de desenvolvimento produtivo na economia brasileira: uma análise de equilíbrio geral computável. Pesquisa e planejamento econômico | ppe | v. $41 \mid$ n. 2 | ago. 2011. Disponível em: http://ppe.ipea.gov.br/index.php/ppe/article/viewFile/1333/1101. Acesso em: 25 mar. 2019.

DEPARTAMENTO INTERSINDICAL DE ESTATÍSTICA E ESTUDOS SOCIOECONÔMICOS (DIEESE). Política de Desenvolvimento Produtivo: Nova Política Industrial do Governo. Nota 
técnica. Maio de 2008. Disponível em: https://www.dieese.org.br/notatecnica/2008/notaTec67PoliticaDesenvolvimento.pdf. Acesso em: 05 mar. 2019.

GADELHA, C. A. G. O complexo industrial da saúde e a necessidade de um enfoque dinâmico na economia da saúde. Revista Ciência e Saúde Coletiva, v. 8 n. 2, p. 521-535, 2003. Disponível em: http://www.scielo.br/scielo.php?script=sci_arttext\&pid=S1413-81232003000200015. Acesso em: 18 mar. 2019.

GADELHA, Carlos Augusto Grabois; COSTA, Laís Silveira. Saúde e desenvolvimento no Brasil: avanços e desafios. Rev Saúde Pública 2012a; 46(Supl):13-20. Disponível em: http://www.scielo.br/scielo.php?script=sci_arttext\&pid=S0034-89102012000700003. Acesso em: 18 mai. 2019.

GADELHA, Carlos Augusto Grabois (coordenador). A dinâmica do sistema produtivo da saúde: inovação e complexo econômico-industrial. Rio de Janeiro: Ed. FIOCRUZ, 2012b.

GADELHA, Carlos Augusto Grabois; COSTA, Laís Silveira; MALDONADO, José. O Complexo Econômico-Industrial da Saúde e a dimensão social e econômica do desenvolvimento. Rev Saúde Pública 2012c;46(Supl):21-8. Disponível em: http:/www.scielo.br/pdf/rsp/v46s1/ao4188.pdf. Acesso em: 15 mar. 2019.

GADELHA, C. A. G.; BRAGA, P. S. C. Saúde e inovação: dinâmica econômica e Estado de BemEstar Social no Brasil. Cad. Saúde Pública, Rio de Janeiro, 32 Sup 2:e00150115, 2016. Disponível em: http://www.scielo.br/pdf/csp/v32s2/pt_1678-4464-csp-32-s2-e00150115.pdf. Acesso em: 20 mar. 2019.

IBGE. Índice Nacional de Preços ao Consumidor Amplo (IPCA). Disponível em: https://www.ibge.gov.br/estatisticas/economicas/precos-e-custos/9256-indice-nacional-de-precosao-consumidor-amplo.html?t=series-historicas. Acesso em: 07 jun. 2019.

INSTITUTO DE ESTUDOS PARA O DESENVOLVIMENTO INDUSTRIAL (IEDI). A política de desenvolvimento produtivo. Disponível em: https://iedi.org.br/admin_ori/pdf/20080529_pdp.pdf. Acesso em: 05 mar. 2019.

SILVA, Everton Nunes da. Complexo Econômico-Industrial da Saúde. Tempus, Actas de saúde coletiva, Brasília, 8(1), 71-78, mar, 2014. Disponível em: http://www.tempusactas.unb.br/index.php/tempus/article/view/1455/1310. Acesso em: 20/03/2019.

TORRES, Ricardo Lobato. A POLÍTICA DE DESENVOLVIMENTO DA INDÚSTRIA FARMACÊUTICA BRASILEIRA DE 2003 A 2014. In: $1^{\circ}$ Encontro Nacional de Economia Industrial e Inovação. ANAIS, dezembro 2016a, vol. 3, num. 4. Disponível em: https://www.proceedings.blucher.com.br/article-details/a-poltica-de-desenvolvimento-da-indstriafarmacutica-brasileira-de-2003-a-2014-25279. Acesso em: 09 jun. 2019.

TORRES, Ricardo Lobato. Estratégias de aprendizado tecnológico na indústria farmacêutica brasileira. In: Desafios de operação e desenvolvimento do Complexo Industrial da Saúde. Organização Lia Hasenclever et al. 1. ed. Rio de Janeiro: E-papers, 2016 b.

VIANA, Ana Luiza d'Ávila et al. A política de desenvolvimento produtivo da saúde e a capacitação dos laboratórios públicos nacionais. Cad. Saúde Pública, Rio de Janeiro, v. 32, supl. 2, e00188814, 2016. Disponível em: http://www.scielo.br/scielo.php?script=sci_arttext\&pid=S0102$311 \mathrm{X} 2016001405003 \& \operatorname{lng}=\mathrm{pt \& nrm}=$ iso. Acesso em: 10 jun. $2019 . \quad \bar{E}$ ub 03-Nov-2016. http://dx.doi.org/10.1590/0102-311X00188814. 